\title{
Dynamic Programming-Based Energy Management System for Range-Extended Electric Bus
}

\author{
Xiaogang Wu, Jingfu Chen, and Chen Hu \\ College of Electrical and Electronics Engineering, Harbin University of Science and Technology, Harbin, China \\ Correspondence should be addressed to Xiaogang Wu; xgwu@hrbust.edu.cn
}

Received 28 August 2014; Accepted 27 September 2014

Academic Editor: Hui Zhang

Copyright ( 2015 Xiaogang Wu et al. This is an open access article distributed under the Creative Commons Attribution License, which permits unrestricted use, distribution, and reproduction in any medium, provided the original work is properly cited.

\begin{abstract}
The heavy computational burden associated with the application of the traditional DP strategy to the energy management of rangeextended electric buses poses a serious problem. On the basis of one Chinese typical urban bus driving cycle, an optimal control strategy is designed according to the SOC consumption trend, which is optimized by the DP algorithm. The dissipative energy and the energy-traction efficiency are our evaluation indices. The energy efficiencies of the powertrain system and components are analyzed by the energy flow diagram method. The results show that when the range-extended electric bus runs 35 Chinese typical urban bus driving cycles, the energy consumption and the energy efficiency of the powertrain system, which are optimized by the traditional DP strategy, can reach 2844.28 MJ and 31.29\%, respectively. Compared with the traditional bus, the energy consumption can be reduced by $31.08 \%$. The energy consumption and the energy efficiency of the powertrain system, which are based on one driving cycle optimal strategy, can reach $2857.69 \mathrm{MJ}$ and $31.14 \%$, respectively. The energy consumption is $0.47 \%$ higher than that with the traditional DP strategy, but the computation time is reduced by $96.85 \%$.
\end{abstract}

\section{Introduction}

The transport sector, a major oil consumer and greenhouse gas emitter, accounted for $26 \%$ of the world's energy use and $23 \%$ of the energy-related greenhouse gas emissions (GHG) in 2004. Road transportation is responsible for over $90 \%$ of these emissions [1-3]. To overcome the resulting air pollution and energy crisis, governments are encouraging automobile manufacturers to develop electric vehicles (EVs) and hybrid electric vehicles (HEVs). However, the battery cycle life and the travel range of such vehicles continue to hinder their development. Therefore, for now, range-extended electric vehicles seem to be the most promising among renewable energy vehicles $[4,5]$.

Given that the energy required by range-extended electric vehicles is supplied mainly by range extenders and the electric power grid, optimal strategies should be applied to such vehicles' energy management systems to minimize their energy consumption $[6,7]$. At present, these optimal strategies can be classified into three categories [8]: rule-based strategies, modern control theory-based intelligent strategies, and optimal strategies. He et al. [9] presented several rule-based control strategies such as constant-voltage control, outline control, and online control. Wei et al. [10] devised a modelbased fuel optimal control for HEVs. The rule-based control strategy is easy to understand and realize. However, it lacks any rigorous mathematical basis and it cannot extract the full performance potential of a hybrid system [11]. Schouten et al. [12] and Gong et al. [13] designed control rules for energy management systems by using fuzzy logic [14] and neural network. The methods achieved better results than the traditional rule-based control strategy, but its results still have difference to those achieved with the optimal strategies. The dynamic programming (DP) algorithm is widely used in the optimal strategies. DP is one of the best methods for dealing with constrained nonlinear optimal problems [15]. It is suitable for optimizing the control strategy of an energy management system when the driving cycle is known in advance. Geng et al. [16] and Barsali et al. [17] presented an equivalent consumption minimization strategy based on the DP algorithm. However, this strategy cannot be applied to real-time control because of its heavy computational burden. Given that the rule-based control strategy can be applied easily to real-time control, the DP algorithm can be combined with 


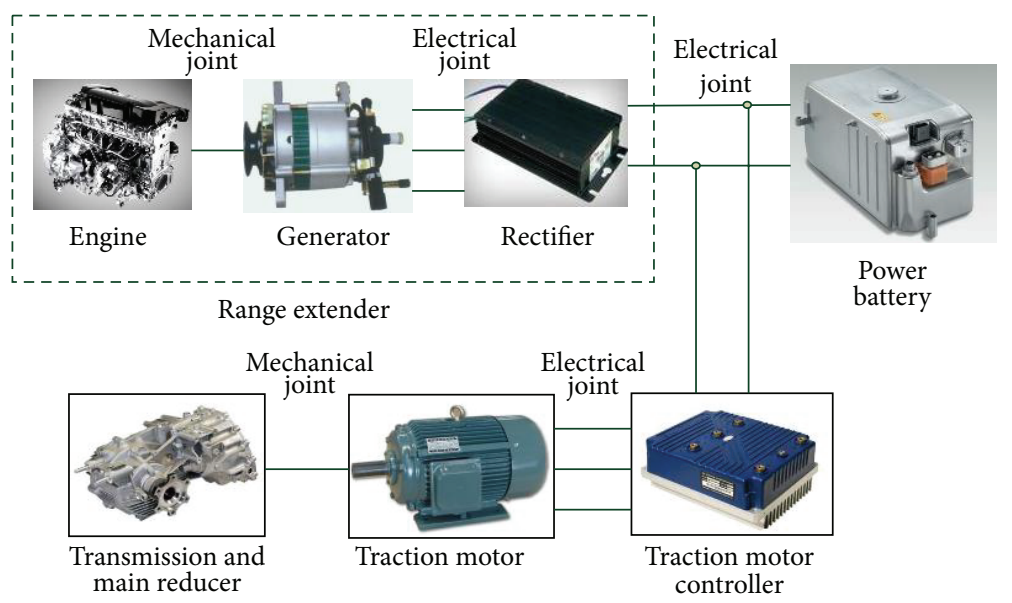

FIGURE 1: REEB powertrain system structure.

the rule-based control strategy. The resulting hybrid control strategy would not only have the global optimal feature of DP strategy but also be easily applicable to real-time control. He et al. [18] used an optimal control strategy for a specified driving cycle to control long-distance driving cycle for a plug-in series-parallel hybrid electric bus. The strategy reduces the computational time significantly, while maintaining the desired precision. Chen et al. [19] designed a DP algorithm-based energy management strategy for rangeextended electric vehicles. Then, a rule-based control strategy was designed considering the global optimal solution and driving cycle recognition. Peng et al. [20, 21] considered energy consumption and GHG emissions to design an energy management strategy by using the DP algorithm and presented an adaptive rule-based control strategy based on the DP solution. Bianchi et al. [22] established a rule-based control strategy for HEVs by using the DP strategy. The corresponding simulation result was close to the optimal result.

We present a DP and rule-based hybrid control strategy for a range-extended electric bus (REEB) running the Chinese typical urban bus driving cycle. This strategy retains the advantages of the DP and the rule-based strategies, while reducing the computational burden. The energy efficiencies of the range extender, the energy-traction, and the powertrain system are analyzed using the energy flow diagram method.

\section{REEB Powertrain System Model}

2.1. Powertrain System Structure Analysis. A schematic of the typical REEB powertrain is shown in Figure 1. The powertrain consists of a range extender, battery, traction motor, transmission, and the main reducer. The battery and the range extender provide power to the traction motor through electrical connections. The traction motor drives the wheels directly through the transmission and the main reducer. The entire power system is connected in series. One feature of the REEB is their large battery capacity, which provides greater power to the REEB, thus reducing fossil fuel consumption and emissions [23]. The range extender module of REEB mainly includes an engine, generator, and rectifier. The generator is mechanically coupled to the output shaft of the engine. The range extender can convert diesel power into electric power for direct use by the traction motor or for charging the onboard battery, thus extending the vehicle's driving range. Moreover, when the power demand of the bus is higher than what the battery can supply, the range extender provides the insufficient power, thus ensuring dynamic performance.

2.2. Powertrain System Modeling. We establish a backward simulation model considering the features of the DP strategy as well as the objective of analyzing fuel consumption. The relative speed $u_{r}$ at each discrete time point $(k)$ can be calculated using the following by the driving cycle data:

$$
u_{r}(k)=\frac{v(k)}{3.6}
$$

where $v$ is the driving speed $(\mathrm{km} / \mathrm{h})$.

To fulfill the requirements of the DP strategy, the vehicle's longitudinal dynamics model is expressed as the following state equation:

$$
\begin{aligned}
u_{r} \dot{(}(k)= & \frac{1}{\delta\left(m_{v}+m_{p}\right)} \\
& \times\left(\frac{1000 P_{\text {req }}(k) \eta_{T}}{u_{r}(k)}\right. \\
& \left.\quad-\frac{u_{r}(k)}{\left|u_{r}(k)\right|}\left(F_{f}+F_{w}\left(u_{r}(k)\right)+F_{i}\right)\right),
\end{aligned}
$$

where $\delta$ is the conversion coefficient of the vehicle rotation quality, $m_{v}$ is the bus mass, $m_{p}$ is the passenger mass, $P_{\text {req }}$ is the demand power of the transmission, $\eta_{T}$ is the efficiency of the transmission and the main reducer, $F_{f}$ is the rolling resistance, $F_{w}$ is the air resistance and the function of $u_{r}$, and $F_{i}$ is the slope resistance. The parameters of the REEB are shown in Table 1. 
TABLE 1: Powertrain parameters of range-extended electric bus.

\begin{tabular}{|c|c|c|}
\hline \multirow{9}{*}{ Bus } & Size $($ length $\times$ width $\times$ height $) / \mathrm{mm}$ & $11980 \times 2550 \times 3200$ \\
\hline & Bus mass/kg & 13400 \\
\hline & Passenger mass $/ \mathrm{kg}$ & 2760 \\
\hline & Windward area $/ \mathrm{m}^{2}$ & 7.83 \\
\hline & Air resistance coefficient $C_{D}$ & 0.75 \\
\hline & Rolling resistance coefficient $f$ & $0.0076+0.00056 u_{a}$ \\
\hline & Rolling radius $r / \mathrm{m}$ & 0.512 \\
\hline & Speed ratio of main reducer $i_{0}$ & 6.2 \\
\hline & Speed ratio of transmission $i_{g}$ & 2.18 \\
\hline \multirow{5}{*}{ Motor } & Continuous power $/ \mathrm{kW}$ & 100 \\
\hline & Peak power $/ \mathrm{kW}$ & 180 \\
\hline & Maximum torque/ $\mathrm{N} \cdot \mathrm{m}$ & 860 \\
\hline & Maximum speed/r/min & 4500 \\
\hline & Operating voltage/V & $300 \sim 450$ \\
\hline \multirow{2}{*}{ Engine } & Displacement/L & 1.9 \\
\hline & Power/kW & $82 / 4000 \mathrm{r} / \mathrm{min}$ \\
\hline \multirow{2}{*}{ Generator and generator controller } & Rated power/kW & 50 \\
\hline & Rated torque/N·m & 220 \\
\hline \multirow{2}{*}{ Power battery } & Capacity & $180 \mathrm{Ah}$ \\
\hline & Operating voltage/V & $350 \sim 460$ \\
\hline
\end{tabular}

The drive power of the vehicle $P_{\text {motor }}$ is provided by the battery $P_{\text {bat }}$ and/or the range extender $P_{\text {re }}$, as expressed by the following:

$$
P_{\text {motor }}=\frac{P_{\text {req }}}{\eta_{\text {motor }}}=P_{\text {re }}+P_{\text {bat }},
$$

where $\eta_{\text {motor }}$ is the efficiency of the traction motor.

Given the computational burden of the DP strategy, the dynamic characteristics of traction motor are ignored. The $2 \mathrm{D}$ look-up table is used for the traction motor model, as shown in Figure 2.

Generally, the equivalent battery models include Rint, PNGV, and GNL. The Rint model focuses on the charge/discharge resistance and the open circuit voltage of the battery, and it has a simple structure. What is more, it meets the demand of the DP strategy. Considering the features of the DP strategy, the following form of the state equation is used in the battery model [24]:

$$
\begin{aligned}
& \text { SÖC }=-\frac{I(k)}{Q_{\text {bat }}}, \\
& \text { SÖC }=-\eta_{\text {SOC }}\left(U_{\text {OCV }}(\mathrm{SOC})\right. \\
& -\left(U_{\mathrm{OCV}}^{2}(\mathrm{SOC})-4\left(R_{\mathrm{int}}(\mathrm{SOC})+R_{t}\right)\right. \\
& \left.\left.\times\left(P_{\text {motor }}(k)-P_{\text {re }}(k)\right)\right)^{1 / 2}\right) \\
& \times\left(2\left(R_{\text {int }}(\mathrm{SOC})+R_{t}\right) \mathrm{Q}_{\mathrm{bat}}\right)^{-1},
\end{aligned}
$$

where $I$ is the battery current, $Q_{\text {bat }}$ is the battery capacity, $\eta_{\mathrm{SOC}}$ is the Coulomb efficiency, $U_{\mathrm{OCV}}$ is the open circuit voltage

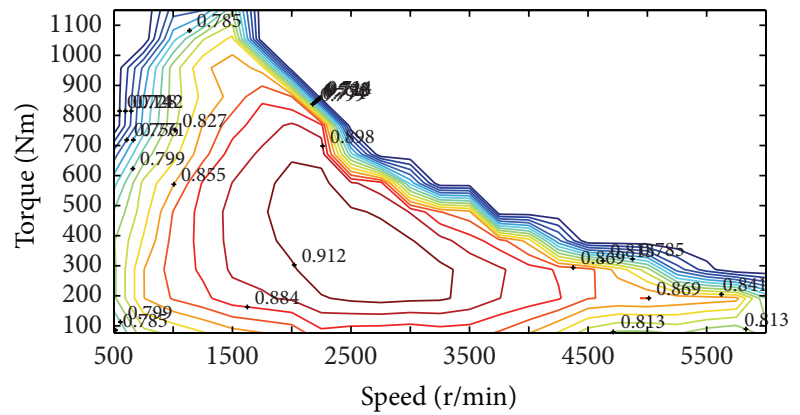

Figure 2: Efficiency map of traction motor.

of the battery, and $R_{\text {int }}$ and $R_{t}$ are the internal resistance and thermal resistance, respectively. $R_{\text {int }}$ and $U_{\mathrm{OCV}}$ are functions of the SOC. The equivalent circuit of the simplified battery model is shown in Figure 3.

As in [25], the charging $\eta_{\text {chr }}$ and discharging $\eta_{\text {dis }}$ efficiencies are calculated using the following:

$$
\begin{gathered}
\eta_{\mathrm{dis}}=\frac{U_{\mathrm{OCV}}-I R_{\mathrm{dis}}}{U_{\mathrm{OCV}}}=\frac{1}{2}\left(1+\sqrt{1-\frac{4 R_{\mathrm{dis}} P_{\mathrm{bat}}}{U_{\mathrm{OCV}}^{2}}}\right), \\
P_{\text {motor }}(k)-P_{\mathrm{re}}(k) \geq 0, \\
\eta_{\mathrm{chg}}=\frac{U_{\mathrm{OCV}}}{U_{\mathrm{OCV}}-I R_{\mathrm{chg}}}=\frac{2}{\left(1+\sqrt{1-4 R_{\mathrm{chg}} P_{\mathrm{bat}} / U_{\mathrm{OCV}}^{2}}\right)}, \\
P_{\text {motor }}(k)-P_{\mathrm{re}}(k)<0,
\end{gathered}
$$

where $R_{\text {dis }}$ and $R_{\text {chg }}$ are the discharging resistance and the charging resistance, respectively. 


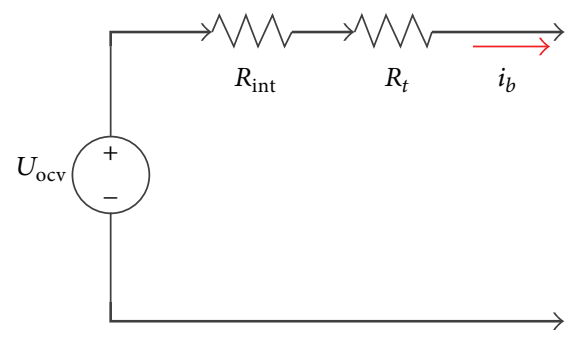

FIGURE 3: Equivalent circuit of simplified battery model.

The dynamic characteristics of the engine and generator models in the range extender are also ignored to reduce the computational burden of the DP strategy. Their models are the MAPs, which are generated by using the data from the bench tests. Because the generator is mechanically coupled to the output shaft of the engine, the generator and engine are in the same working points. The optimal fuel economy curve of the range extender is developed by the method described in [19], as shown in Figures 4 and 5.

\section{DP Strategy and Analysis of Energy Flow Diagram}

3.1. DP Strategy-Based Energy Management Strategy. In the horizon $\left[t_{0}, t_{f}\right]$, the state variables of the REEB powertrain system include the SOC of the battery and the bus speed. As the bus speed can be determined from the driving cycle, the state variable is $x(t)=[\mathrm{SOC}(t)]^{\prime}$. According to the optimal objective of minimum equivalent fuel consumption, the range extender is regarded as the control variable, $u(t)=$ $\left[P_{\mathrm{re}}(t)\right]$. The powertrain system of the REEB in the discrete form is shown as follows:

$$
\dot{x}=f(x(k), u(k)),
$$

where $f$ represents (1)-(5).

The constraint conditions of the state space are expressed by the following:

$$
\begin{gathered}
P_{\text {bat }} \in\left[\frac{U_{\text {bus,max }}\left(U_{\mathrm{OCV}}-U_{\text {bus,max }}\right)}{R_{\text {chg }}},\right. \\
\left.\frac{U_{\text {bus,min }}\left(U_{\mathrm{OCV}}-U_{\text {bus,min }}\right)}{R_{\text {dis }}}\right], \\
0 \leq P_{\text {re }} \leq P_{\text {re,max }}, \\
\mathrm{SOC}_{L}<\mathrm{SOC}<\mathrm{SOC}_{H}, \\
T_{m, \text { min }}<T_{m}(t)<T_{m, \text { max }},
\end{gathered}
$$

where $U_{\text {bus,max }}, U_{\text {bus,min }}, U_{\mathrm{OCV}}, R_{\mathrm{chg}}$, and $R_{\text {dis }}$ are battery parameters that represent the maximum voltage, minimum voltage, open circuit voltage, and charging resistance and discharging resistance, respectively. $P_{\text {re, } \max }$ denotes the maximum power of the range extender. $\mathrm{SOC}_{H}$ and $\mathrm{SOC}_{L}$ represent the maximum and minimum values of the SOC, respectively. $T_{m}$ denotes the traction motor torque; $T_{m, \min }$ and $T_{m, \max }$

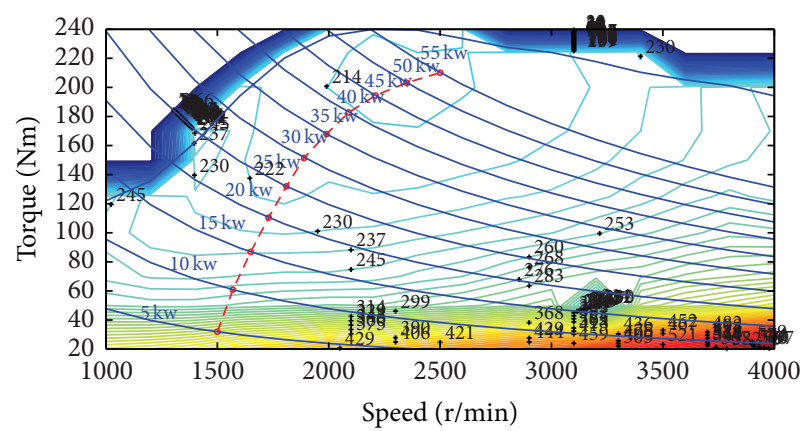

Figure 4: BSFC map of engine.

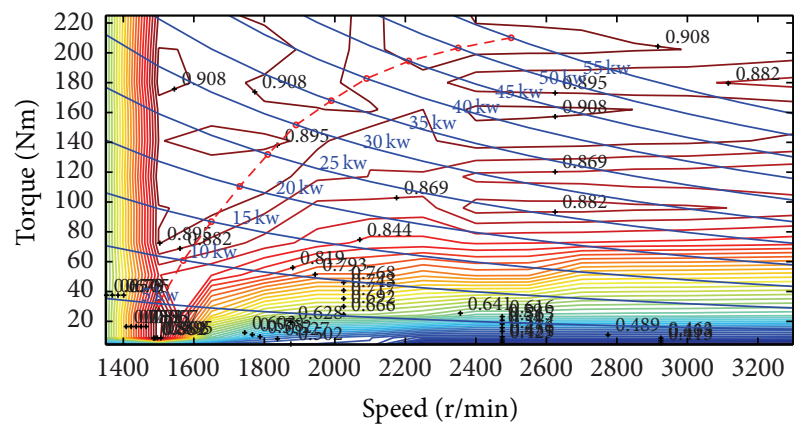

FIGURE 5: Efficiency map of generator.

represent the maximum torque and the minimum torque of the traction motor, respectively.

The key to the DP strategy is the reasonable cost function. In this paper, the electric power is equivalent to the fuel consumption, and achieving the minimum fuel consumption is regarded as the objective for reducing the fuel consumption and emissions. The cost function $J$ is shown as follows:

$$
J=\sum_{k=0}^{N}\left\{C_{\mathrm{re}, k}+k_{k} C_{\mathrm{bat}, k}\right\},
$$

where $C_{\mathrm{re}, k}$ is the fuel consumption of the range extender in the $k$ th state, $C_{\text {bat }, k}$ is the equivalent fuel consumption of the battery in the $k$ th state, and $k_{k}$ is the coefficient for constraining the SOC. The fuel consumption of the range extender, equivalent fuel consumption of the battery, and $k_{k}$ can be calculated as follows:

$$
\begin{gathered}
C_{\mathrm{re}}=P_{\mathrm{eng}} b e \Delta t, \\
C_{\mathrm{bat}}=P_{\mathrm{bat}}\left(\eta_{\mathrm{dis}} \eta_{\mathrm{chg}}\right)^{-\operatorname{sgn}\left(P_{\mathrm{bat}}\right)} \frac{C_{\mathrm{re}, \mathrm{avg}}}{P_{\mathrm{re}, \mathrm{avg}}} \Delta t, \\
k_{k}=1-\frac{2 \mu\left(\mathrm{SOC}-0.5\left(\mathrm{SOC}_{H}-\mathrm{SOC}_{L}\right)\right)}{\left(\mathrm{SOC}_{H}-\mathrm{SOC}_{L}\right)},
\end{gathered}
$$

where $P_{\text {eng }}$ is the output power of the engine in the $k$ th state, $b e$ is the specific fuel consumption, $C_{\text {re,avg }}$ is the average fuel consumption of the range extender, $P_{\text {re,avg }}$ is the average output power of the range extender, and $\mu$ is the balance 
coefficient required to maintain the SOC within the reasonable range [26].

3.2. Energy Consumption Analysis Based on Energy Flow Diagram. In this section, the energy conversion process is analyzed from the power grid and the fuel used to the wheels. The energy efficiencies of the powertrain system and components are calculated. The fuel and electric consumption are converted to MJ-equivalent values. The driving power at the wheels $P_{\text {dem }}$ is calculated as follows:

$$
\begin{aligned}
P_{\mathrm{dem}}(t) & =P_{f}(t)+P_{w}(t)+P_{i}(t)+P_{j}(t) \\
& =F_{f}(t) u_{r}+F_{w}(t) u_{r}+F_{i}(t) u_{r}+F_{j}(t) u_{r} .
\end{aligned}
$$

The energy at the driving wheels $E_{\text {dem }}$ and the input power of the traction motor $E_{\text {motor,input }}$ can be calculated using (11). According to the method in [19], if we ignore regenerative braking energy, the output torque of the traction motor is also very similar to that in the normal model. Moreover, there is a slight difference in the negative value of the output torque. Therefore, regenerative braking energy is ignored to reduce the computational burden of the DP strategy. $E_{\text {dem }}$ can be obtained by integration when $P_{\text {dem }}$ is positive. Consider

$$
\begin{aligned}
E_{\mathrm{dem}}=\int_{P_{\mathrm{dem}}(t)>0} \frac{P_{\mathrm{dem}}(t)}{1000} d t & \\
E_{\text {motor,input }}= & \frac{E_{\text {motor,output }}}{\eta_{m}} \\
& =\int_{P_{\mathrm{dem}}(t)>0} \frac{P_{\mathrm{dem}}(t)}{1000 \eta_{\text {tran,re }}(t) \eta_{m}(t)} d t,
\end{aligned}
$$

where $E_{\text {motoroutput }}$ is the output power of the traction motor, $\eta_{T}$ is the efficiency of the transmission and the main reducer, and $\eta_{m}$ is the efficiency of the traction motor.

The output power $E_{b}$ can be calculated as follows:

$$
E_{b}=\int_{P_{\text {bat }}(t)>0} \frac{P_{\text {bat }}(t)}{1000} d t,
$$

where $P_{\text {bat }}$ is the battery power. The output energy $E_{b}$ can be calculated using $E_{\text {dem }}$, which can be obtained by integration when $P_{\text {bat }}$ is positive. lows:

The energy from the grid $E_{\text {grid }}$ can be calculated as fol-

$$
E_{\text {grid }}=\int \frac{3.6(\operatorname{SOC}(t)-\operatorname{SOC}(t-1)) Q V(t)}{1000 \eta_{\text {chg }}(t)} d t,
$$

where $Q$ is the battery capacity, $V$ is the battery voltage, and $\eta_{\text {chg }}$ is the charging efficiency of battery.

The charging energy transferred from the range extender to the battery $E_{b, g}$ can be determined as follows:

$$
E_{b, g}=\int_{P_{\text {bat }}(t)<0} \frac{P_{\text {bat }}(t)}{1000} d t .
$$

When $P_{\text {bat }}$ is negative, the range extender can provide the power to the battery. The energy loss of the battery is calculated by the following:

$$
\begin{aligned}
E_{\text {loss }, b}= & E_{\text {grid }}\left(1-\eta_{\text {chg }, \text { avg }}\right)+\int_{P_{\text {bat }}(t)<0} \frac{P_{\text {bat }}(t)\left(1-\eta_{\text {chg }}(t)\right)}{1000} d t \\
& +\int_{P_{\text {bat }}(t)>0} \frac{P_{\text {bat }}(t)\left(1-\eta_{\text {dis }}(t)\right)}{1000} d t .
\end{aligned}
$$

This paper focuses on the energy loss during charging and discharging, including charging the battery from the grid, charging the battery from the range extender, and discharging the battery to the traction motor. $\eta_{\text {chg,avg }}$ is the average efficiency of battery charging, $\eta_{\text {chg }}$ is the efficiency of battery charging, and $\eta_{\text {dis }}$ is the battery discharge efficiency. follows:

The output energy of the range extender is calculated as

$$
E_{g}=\int \frac{P_{\mathrm{re}}(t)}{1000} d t
$$

where $P_{\text {re }}$ is the output power of the range extender. The output energy of the engine $E_{\text {eng }}$ is obtained as follows:

$$
E_{\text {eng }}=\int \frac{P_{\text {re }}(t)}{1000 \eta_{\text {gen }}(t)} d t
$$

where $\eta_{\text {eng }}$ is the generator efficiency. The fuel energy can be calculated as follows:

$$
E_{\text {fuel }}=\int \frac{P_{\text {re }}(t) b e(t)}{\eta_{\text {gen }}(t) \rho_{\text {disel }}} \rho_{\mathrm{LHV}} d t,
$$

where be is the specific fuel consumption of the engine $(\mathrm{kg} / \mathrm{kWh})$ and $\rho_{\mathrm{LHV}}$ is the lower heating value of diesel $(42.8 \mathrm{MJ} / \mathrm{L})$ [27]. The fuel efficiency $\eta_{\text {fuel }}$ can be calculated as follows:

$$
\begin{aligned}
\eta_{\text {fuel }}= & \eta_{\text {eng,avg }} \eta_{\text {gen,avg }} \\
& \times\left(\frac{E_{b, g}}{E_{g}} \eta_{\text {chg,avg }} \eta_{\text {dis,avg }}+\frac{E_{g}-E_{b, g}}{E_{g}}\right) \eta_{m, \text { avg }} \eta_{T}, \\
\eta_{\text {eng,avg }}= & \frac{E_{\text {eng }}}{E_{\text {fuel }}} \\
\eta_{\text {ge,avg }}= & \frac{E_{g}}{E_{\text {eng }}}, \\
\eta_{m, \text { avg }}= & \frac{E_{\text {motor,input }}}{E_{\text {motor,output }}}, \\
\eta_{\text {grid }}= & \eta_{\text {chg,avg }} \eta_{\text {dis,avg }} \eta_{m, \text { avg }} \eta_{\text {tran,avg }},
\end{aligned}
$$

where $\eta_{\text {eng,avg }}$ is the average efficiency of the engine, $\eta_{\text {gen,avg }}$ is the average efficiency of the generator, $\eta_{\text {dis,avg }}$ is the average efficiency of battery discharge, $\eta_{m \text {,avg }}$ is the average efficiency of the traction motor, $\eta_{T}$ is the efficiency of the transmission 


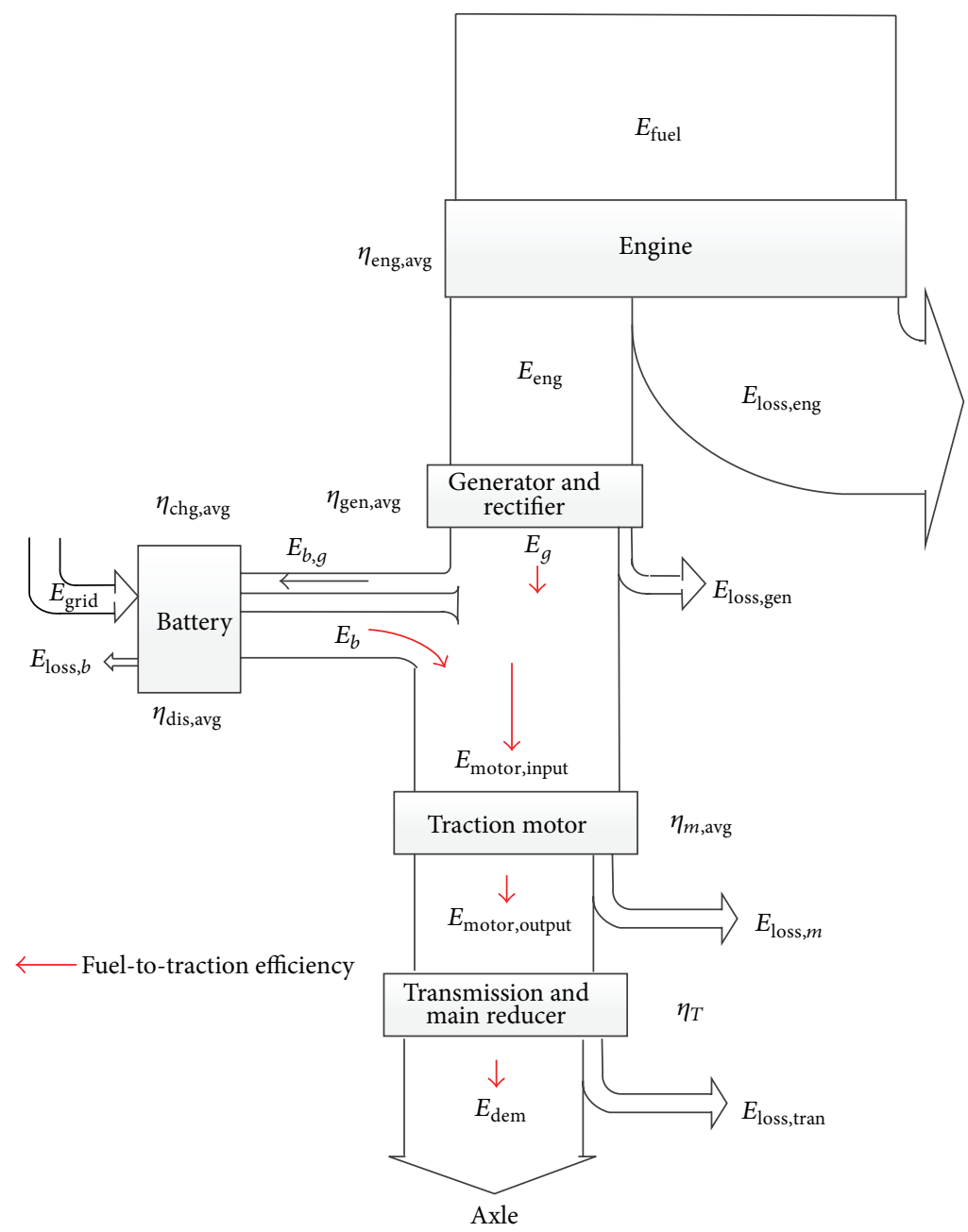

Figure 6: Energy flow of REEB.

and the main reducer, and $\eta_{\text {grid }}$ is the efficiency of the supplied electric power.

Based on the energy consumed as fuel and electric power, the energy efficiency of the powertrain system can be calculated as follows:

$$
\eta_{\text {energy }}=\frac{E_{\text {dem }}}{E_{\text {grid }}+E_{\text {fuel }}} .
$$

The energy flow of the powertrain system and the energy loss and efficiency of the components can be obtained using the above formulas [28]. The energy flow diagram of the powertrain system is shown in Figure 6.

\section{Result and Analysis}

According to a survey result, the distance covered by a city bus is about $200 \mathrm{~km} /$ day in China. Given the large battery capacity of the REEB and the one-charge-per-day operation mode, the driving cycle for the simulation is 35 Chinese typical urban bus driving cycles, which spans $204.05 \mathrm{~km}$. The Chinese typical urban bus driving cycle is shown in Figure 7.

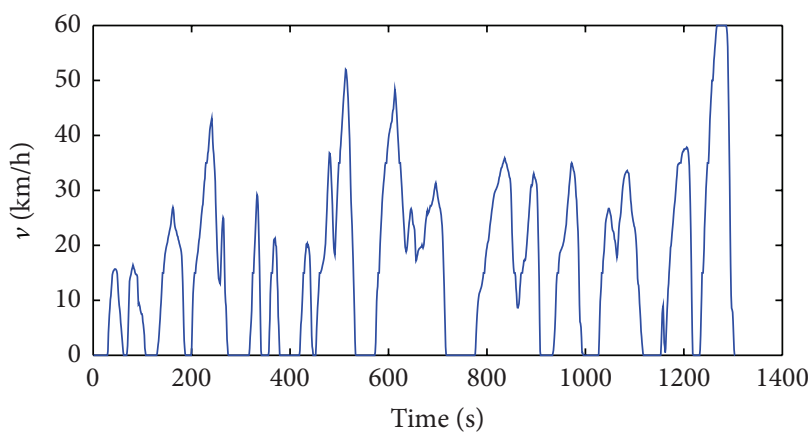

FIgURE 7: Chinese typical urban bus driving cycle.

In the simulation, the state variable SOC and the control variable $P_{\text {re }}$ are constrained to $[0.2,1]$ and $[0,50]$, respectively. The trajectories of the SOC and $P_{\text {re }}$, as obtained using the traditional DP strategy, are shown in Figures 8 and 9, respectively.

Figure 8 shows the optimal SOC trajectory. When the bus reaches the destination, the SOC reaches 0.2017. Figure 9 


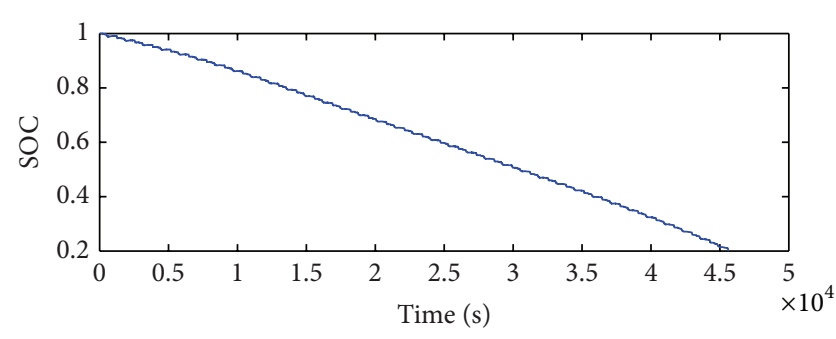

FIGURE 8: SOC trajectory based on traditional DP strategy.

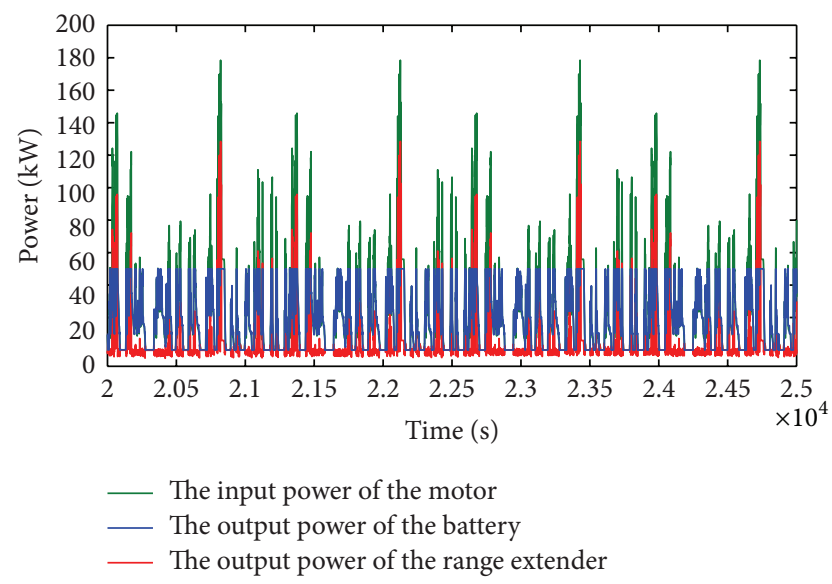

FIGURE 9: Relationship among power of components based on traditional DP strategy.

shows the demand power of the components according to the result of the DP strategy. This refers to the optimal relationship of the power split at each discrete time point. The maximum output power of the traction motor is $178.48 \mathrm{kWh}$. The maximum output power of the range extender is $50 \mathrm{kWh}$. The maximum output power of the battery is $128.48 \mathrm{kWh}$. Since regenerative braking is ignored, the range extender charges battery when the output power of the battery is negative. The maximum charging power is $8.03 \mathrm{kWh}$. Because the driving cycle duration is long, a segment of $5000 \mathrm{~s}$ from the entire cycle is shown in Figure 9.

As shown in Figure 8, the SOC trajectory declines uniformly. This means that the SOC consumption in each driving cycle is very close. To reduce the computational burden of the DP strategy, the powertrain system of the REEB is optimized by the DP strategy to achieve the optimal control strategy in one driving cycle. Then, according to the method described in [18], the control strategy of one driving cycle is considered as a rule to control 35 driving cycles. In the traditional DP strategy, the average SOC consumption value in every driving cycle is 0.00229 . Therefore, when the DP strategy is used to optimize one driving cycle, the initial and final values are 0.5 and 0.4771 , respectively. Under these conditions, the SOC trajectory is shown in Figure 10. The minimum SOC value is 0.4771 . Because the range extender charges the battery at the end of the driving cycle, SOC finally reaches 0.4772 .

Table 2 and Figure 11 show a comparison of the simulation data between the traditional DP strategy and the control

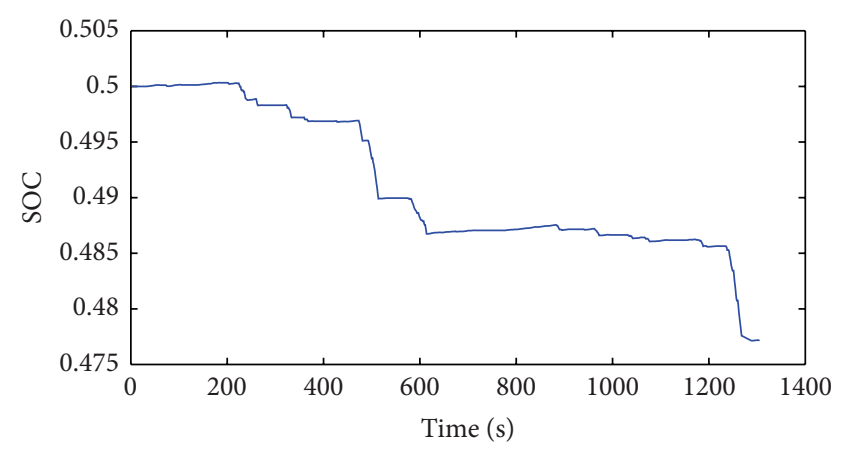

FIGURE 10: SOC trajectory of one Chinese typical urban bus driving cycle.

TABLE 2: Comparison of simulation result under different driving cycles.

\begin{tabular}{lcc}
\hline Number of driving cycles & 35 & 1 \\
Driving distance $(\mathrm{km})$ & 204.05 & 5.83 \\
Initial SOC & 1 & 0.5 \\
Final SOC & 0.2017 & 0.4772 \\
Electric power consumption & 63.38 & 1.86 \\
(kWh) & 61.12 & 1.75 \\
Fuel consumption (L) & 29.95 & 30.02 \\
$\begin{array}{l}\text { Fuel consumption per } 100 \mathrm{~km} \\
\text { (L/100 km) }\end{array}$ & 70843.53 & 2225.64 \\
\hline Calculation time (s) & & \\
\hline
\end{tabular}

strategy based on one driving cycle. The fuel consumption per $100 \mathrm{~km}$ of the traditional DP strategy and the control strategy based on one driving cycle reaches $29.95 \mathrm{~L}$ and $30.02 \mathrm{~L}$, respectively. The fuel consumption in the latter case is only $0.23 \%$ higher, but the calculation time reduces by $96.85 \%$.

Figure 11(a) shows the SOC trajectory for two types of control strategies. The final SOC reaches 0.1983 by the control strategy based on one driving cycle, which consumes more electric power than the traditional DP strategy. The output power comparisons of the range extender and the battery between the two types of control strategies are shown in Figures 11(b) and 11(c). Under the two types of control strategies, the demand power trajectories of the range extender and battery show little difference. This means that the control strategy based on one driving cycle retains the features of the traditional DP strategy.

The powertrain is analyzed by the energy flow diagram. The energy flow diagrams of the two types of control strategies are shown in Figure 12. The energy efficiencies of the range extender, fuel, electric power, and powertrain system can be obtained using (19) and (20), as shown in Figure 13. The four energy efficiencies obtained by the traditional DP strategies are all higher than that obtained by the control strategy based on one driving cycle. The energy efficiency of the range extender shows the largest difference, but this difference is only $0.21 \%$. The difference of the powertrain system is only $0.15 \%$. From the viewpoint of energy efficiency, it is 


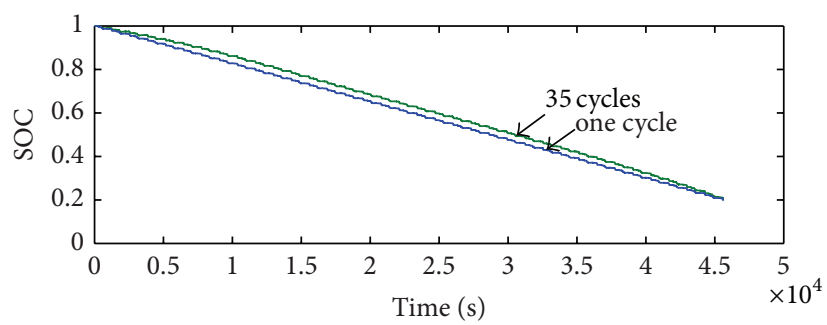

(a) Comparison of SOC trajectories

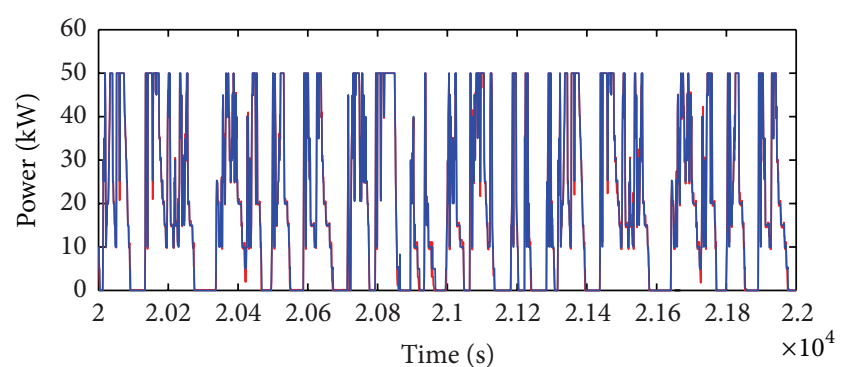

- The demand power of the range extender for 35 driving cycles _ The demand power of the range extender for one driving cycle

(b) Comparison of range extender output power

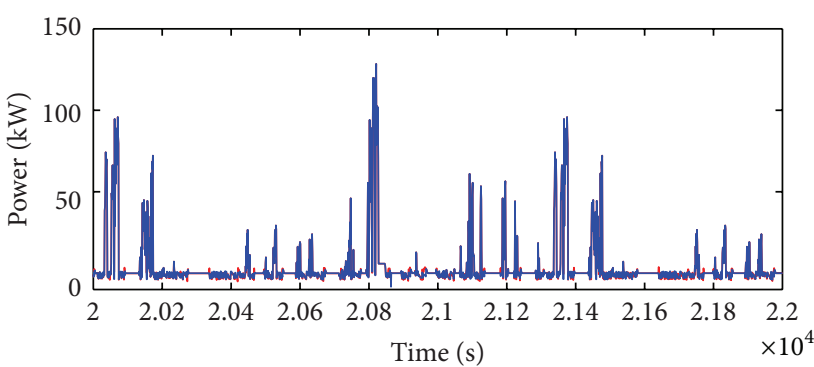

- The demand power of the battery for 35 driving cycles _ The demand power of the battery for one driving cycle

(c) Comparison of battery output power

FIGURE 11: Comparison of simulation results obtained using two control strategies.

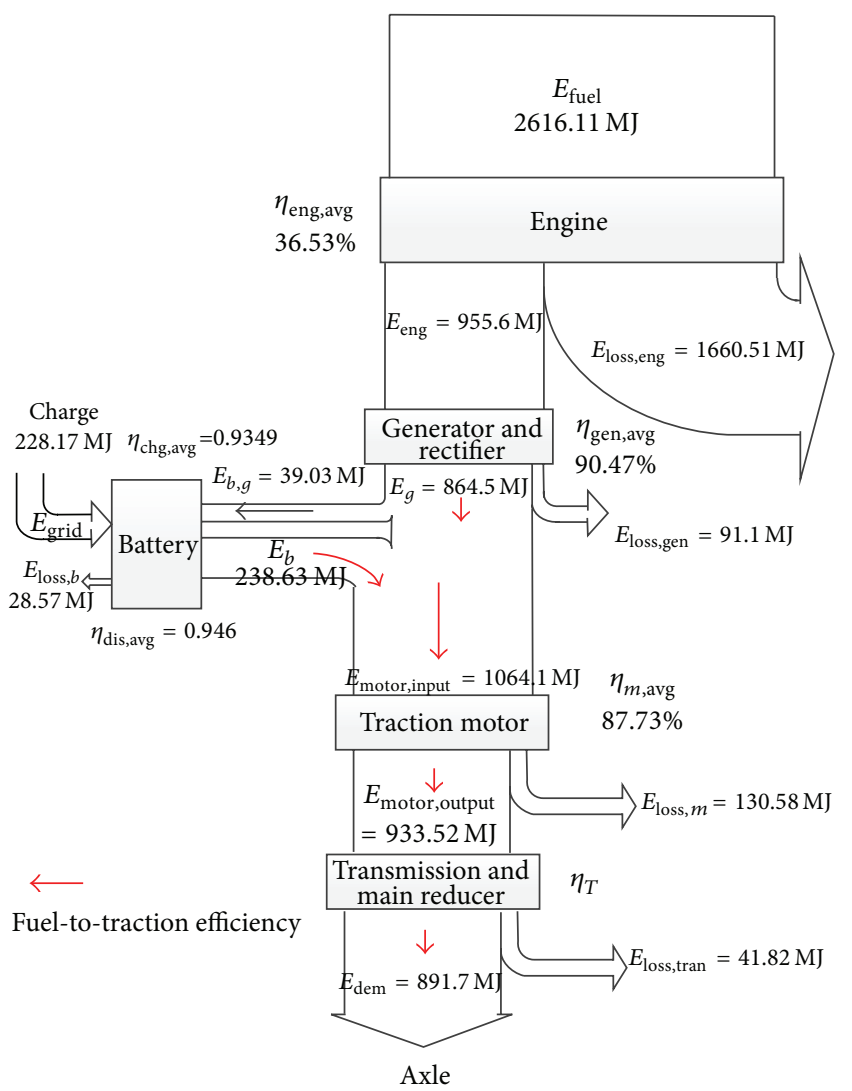

(a) Traditional DP strategy

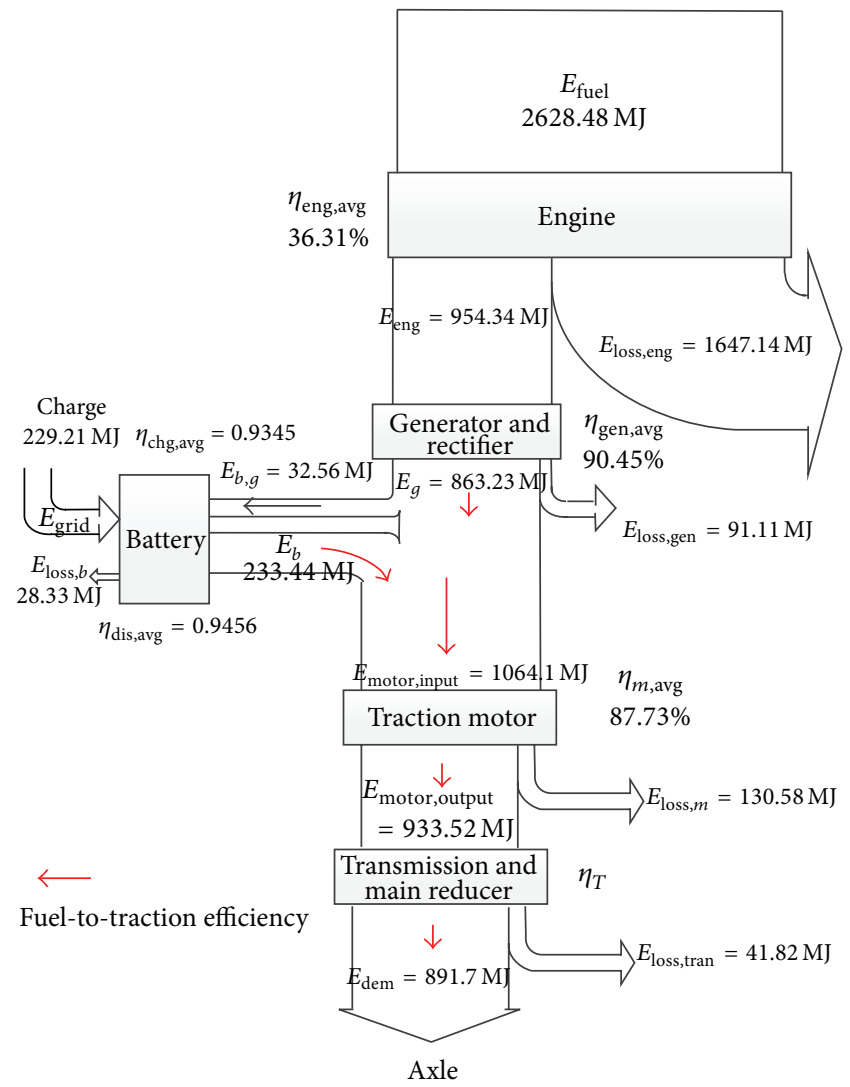

(b) Control strategy based on one driving cycle

FIGURE 12: Energy flow diagram of two types of control strategies. 


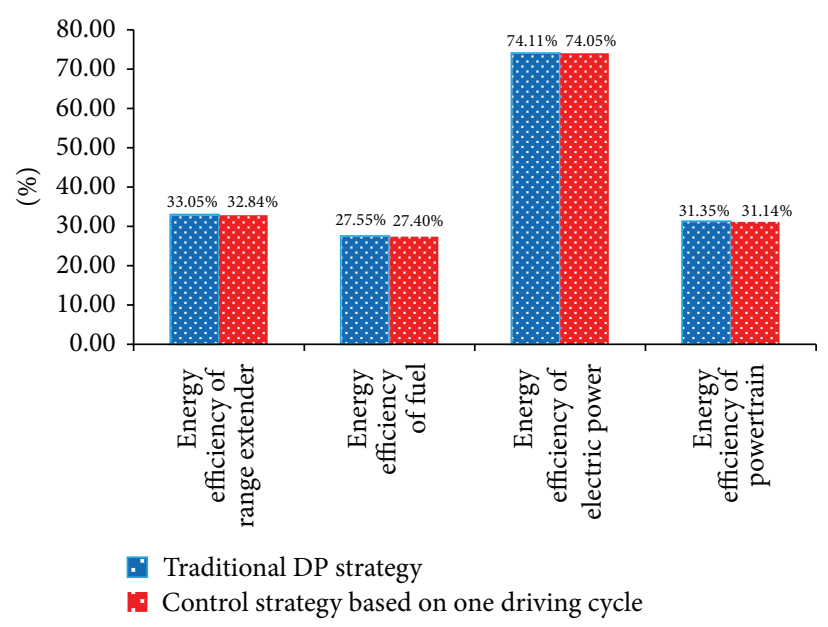

FIGURE 13: Comparison of energy efficiency between two types of control strategies.

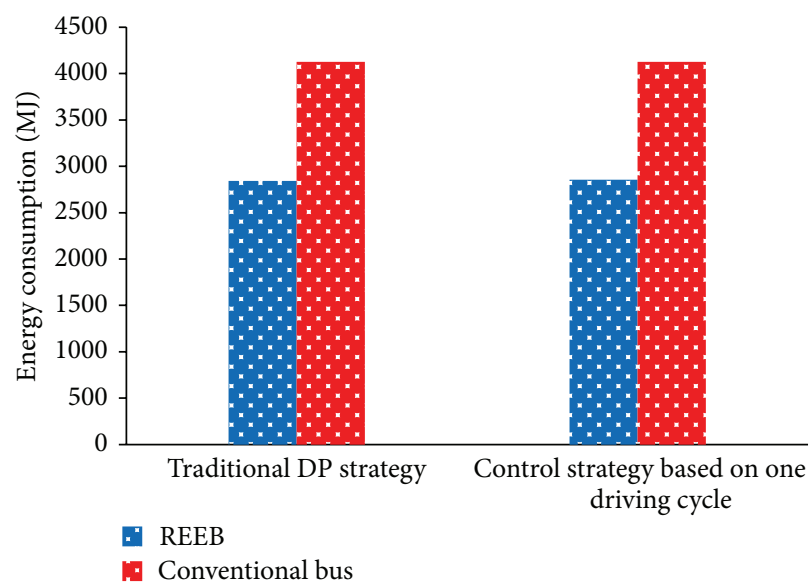

(a) Comparison of energy consumption

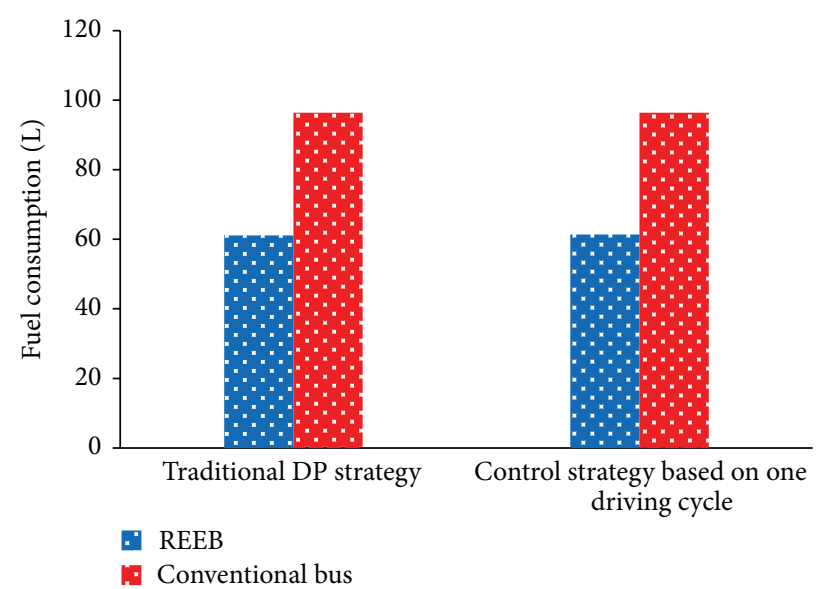

(b) Comparison of fuel consumption

FIGURE 14: Comparison between REEB with two kinds of control strategies and traditional bus.

feasible to control 35 Chinese typical urban bus driving cycles using the control strategy based on one driving cycle.

Table 3 shows a comparison of the simulation results of the two types of control strategies. The fuel consumption, electric power consumption, and total energy consumption of the control strategy based on one driving cycle reach $0.47 \%$, $0.46 \%$, and $0.48 \%$, respectively, which are higher than those of the traditional DP strategy. The SOC remains in a reasonable range. However, the calculation time is significantly reduced. Considering the factors of energy consumption, energy efficiency, and energy loss, it is reasonable to apply the control strategy based on one driving cycle to the 35 Chinese typical urban bus driving cycles.

Finally, the fuel consumption and energy of the two types of control strategies are compared with those of the traditional bus, as shown in Figure 14. The fuel consumption of REEB by the traditional DP strategy and the control strategy based on one driving cycle can reach $68.91 \%$ and $69.24 \%$, respectively. Furthermore, the fuel saving rate can reach $36.61 \%$ and $36.31 \%$, respectively.

\section{Conclusion}

This study simulates the REEB powertrain system by the traditional DP strategy in a Chinese typical urban bus driving cycle. In light of the computational burden of the DP strategy, the control strategy based on one driving cycle is designed according to the result of the traditional DP strategy. The conclusions of this study are as follows.

Under the conditions of 35 Chinese typical urban bus driving cycles and ignoring regenerative braking, the energy consumption of the REEB can reach 2844.28 MJ when using the traditional DP strategy. The energy consumption when using the control strategy based on one driving cycle can reach $2857.69 \mathrm{MJ}$, which is $0.47 \%$ higher than that of the traditional DP strategy.

The energy efficiency of the REEB powertrain system by the traditional DP strategy is only $0.15 \%$ higher than that of the control strategy based on one driving cycle. However, the control strategy based on one driving cycle can reduce the calculation time by $96.85 \%$. 
TABLE 3: Comparison of simulation results obtained with two types of control strategies.

\begin{tabular}{|c|c|c|c|c|c|c|}
\hline Control strategy & $\begin{array}{c}\text { Number of } \\
\text { driving cycles }\end{array}$ & Initial SOC & Final SOC & $\begin{array}{c}\text { Electric power } \\
\text { consumption }(\mathrm{kWh})\end{array}$ & $\begin{array}{c}\text { Fuel consumption } \\
\text { (L) }\end{array}$ & $\begin{array}{l}\text { Powertrain energy } \\
\text { consumption (MJ) }\end{array}$ \\
\hline $\begin{array}{l}\text { Traditional DP } \\
\text { strategy }\end{array}$ & 35 & 1.0 & 0.2017 & 63.38 & 61.124 & 2844.28 \\
\hline $\begin{array}{l}\text { Control strategy } \\
\text { based on one } \\
\text { driving cycle }\end{array}$ & 35 & 1.0 & 0.1983 & 63.67 & 61.413 & 2857.69 \\
\hline
\end{tabular}

The energy consumption of the REEB for the two types of control strategies is $69 \%$ of the traditional bus. The fuel saving rate can exceed $36 \%$.

Considering the factors of energy consumption, energy efficiency, and energy loss, it is reasonable to replace the traditional DP control strategy with the control strategy based on one driving cycle.

\section{Conflict of Interests}

The authors declare that there is no conflict of interests regarding the publication of this paper.

\section{References}

[1] X. Ou, X. Zhang, and S. Chang, "Alternative fuel buses currently in use in China: life-cycle fossil energy use, GHG emissions and policy recommendations," Energy Policy, vol. 38, no. 1, pp. 406$418,2010$.

[2] H. Zhang, X. Zhang, and J. Wang, "Robust gain-scheduling energy-to-peak control of vehicle lateral dynamics stabilisation," Vehicle System Dynamics, vol. 52, no. 3, pp. 309-340, 2014.

[3] E. A. Nanaki and C. J. Koroneos, "Comparative economic and environmental analysis of conventional, hybrid and electric vehicles-the case study of Greece," Journal of Cleaner Production, vol. 53, pp. 261-266, 2013.

[4] H. Zhang, X. Liu, J. Wang, and H. R. Karimi, "Robust $H_{\infty}$ sliding mode control with pole placement for a fluid power electrohydraulic actuator (EHA) system," The International Journal of Advanced Manufacturing Technology, vol. 73, no. 5-8, pp. 10951104, 2014.

[5] E. D. Tate, O. M. Harpster, and P. J. Savagian, “The electrification of the automobile: from conventional hybrid, to plugin hybrids, to extended-range electric vehicles," SAE Technical Paper, 2008.

[6] M. Cipek, M. Coric, B. Skugor et al., "Dynamic programmingbased optimization of control variables of an extended range electric vehicle," in Proceedings of the SAE World Congress \& Exhibition, 2013.

[7] H. Zhang and J. Wang, "Combined feedback-feedforward tracking control for networked control systems with probabilistic delays," Journal of the Franklin Institute, vol. 351, no. 6, pp. 34773489, 2014.

[8] B. Vural, A. R. Boynuegri, I. Nakir et al., "Fuel cell and ultra-capacitor hybridization: a prototype test bench based analysis of different energy management strategies for vehicular applications," International Journal of Hydrogen Energy, vol. 35, no. 20, pp. 11161-11171, 2010.

[9] B. He, L. G. Lu, and J. Q. Li, "Simulation research on energy management strategy of fuel cell hybrid electric vehicle," Journal of Highway and Transportation Research and Development, vol. 23, no. 1, pp. 151-154, 2006.

[10] X. Wei, L. Guzzella, V. I. Utkin, and G. Rizzoni, "Modelbased fuel optimal control of hybrid electric vehicle using variable structure control systems," Journal of Dynamic Systems, Measurement and Control, Transactions of the ASME, vol. 129, no. 1, pp. 13-19, 2007.

[11] N. Jalil, N. A. Kheir, and M. Salman, "Rule-based energy management strategy for a series hybrid vehicle," in Proceedings of the IEEE American Control Conference, vol. 1, pp. 689-693, June 1997.

[12] N. J. Schouten, M. A. Salman, and N. A. Kheir, "Fuzzy logic control for parallel hybrid vehicles," IEEE Transactions on Control Systems Technology, vol. 10, no. 3, pp. 460-468, 2002.

[13] Q. Gong, Y. Li, and Z. Peng, "Power management of plugin hybrid electric vehicles using neural network based trip modeling," in Proceedings of the American Control Conference (ACC '09), pp. 4601-4606, IEEE, June 2009.

[14] H. Zhang, Y. Shi, and J. Wang, "On energy-to-peak filtering for nonuniformly sampled nonlinear systems: a markovian jump system approach," IEEE Transactions on Fuzzy Systems, vol. 22, no. 1, pp. 212-222, 2014.

[15] M. Koot, J. T. B. A. Kessels, B. de Jager, W. P. M. H. Heemels, P. P. J. van den Bosch, and M. Steinbuch, "Energy management strategies for vehicular electric power systems," IEEE Transactions on Vehicular Technology, vol. 54, no. 3, pp. 771-782, 2005.

[16] B. Geng, J. K. Mills, and D. Sun, "Energy management control of microturbine-powered plug-in hybrid electric vehicles using the telemetry equivalent consumption minimization strategy," IEEE Transactions on Vehicular Technology, vol. 60, no. 9, pp. 4238-4248, 2011.

[17] S. Barsali, C. Miulli, and A. Possenti, "A control strategy to minimize fuel consumption of series hybrid electric vehicles," IEEE Transactions on Energy Conversion, vol. 19, no. 1, pp. 187195, 2004.

[18] H. He, H. Tang, and X. Wang, "Global optimal energy management strategy research for a plug-in series-parallel hybrid electric bus by using dynamic programming," Mathematical Problems in Engineering, vol. 2013, Article ID 708261, 11 pages, 2013.

[19] B. C. Chen, Y. Y. Wu, and H. C. Tsai, "Design and analysis of power management strategy for range extended electric vehicle using dynamic programming," Applied Energy, vol. 113, pp. 1764-1774, 2014.

[20] D. Kum, H. Peng, and N. K. Bucknor, "Optimal energy and catalyst temperature management of plug-in hybrid electric vehicles for minimum fuel consumption and tail-pipe emissions," IEEE Transactions on Control Systems Technology, vol. 21, no. 1, pp. 14-26, 2013.

[21] C.-C. Lin, H. Peng, J. W. Grizzle, and J.-M. Kang, "Power management strategy for a parallel hybrid electric truck," IEEE 
Transactions on Control Systems Technology, vol. 11, no. 6, pp. 839-849, 2003.

[22] D. Bianchi, L. Rolando, L. Serrao et al., "Layered control strategies for hybrid electric vehicles based on optimal control," International Journal of Electric and Hybrid Vehicles, vol. 3, no. 2, pp. 191-217, 2011.

[23] X. Wu, C. Hu, and J. Chen, "Energy flow chart-based energy efficiency analysis of a range-extended electric bus," Mathematical Problems in Engineering, vol. 2014, Article ID 972139, 12 pages, 2014.

[24] Z. Yuan, L. Teng, S. Fengchun, and H. Peng, "Comparative study of dynamic programming and pontryagin's minimum principle on energy management for a parallel hybrid electric vehicle," Energies, vol. 6, no. 4, pp. 2305-2318, 2013.

[25] L. Xu, M. Ouyang, J. Li, F. Yang, L. Lu, and J. Hua, "Application of Pontryagin's minimal principle to the energy management strategy of plug-in fuel cell electric vehicles," International Journal of Hydrogen Energy, vol. 38, no. 24, pp. 10104-10115, 2013.

[26] L. Xu, Powertrain system modeling and optimal control of fuel cell hybrid electric vehicle [doctoral, thesis], Tsinghua University, Beijing, China, 2009.

[27] M. Pourabdollah, N. Murgovski, A. Grauers, and B. Egardt, "Optimal sizing of a parallel PHEV powertrain," IEEE Transactions on Vehicular Technology, vol. 62, no. 6, pp. 2469-2480, 2013.

[28] X. Hu, N. Murgovski, L. Johannesson, and B. Egardt, "Energy efficiency analysis of a series plug-in hybrid electric bus with different energy management strategies and battery sizes," Applied Energy, vol. 111, pp. 1001-1009, 2013. 


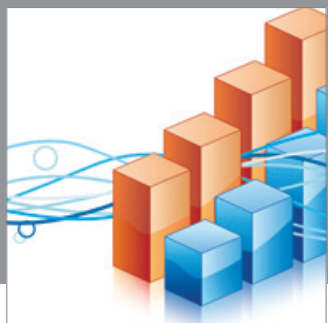

Advances in

Operations Research

mansans

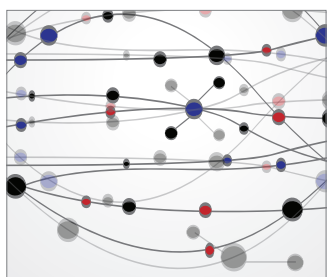

The Scientific World Journal
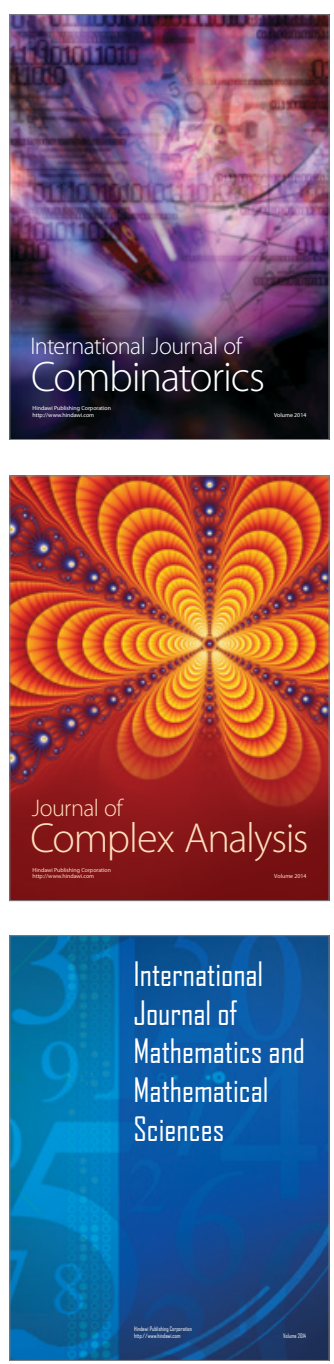
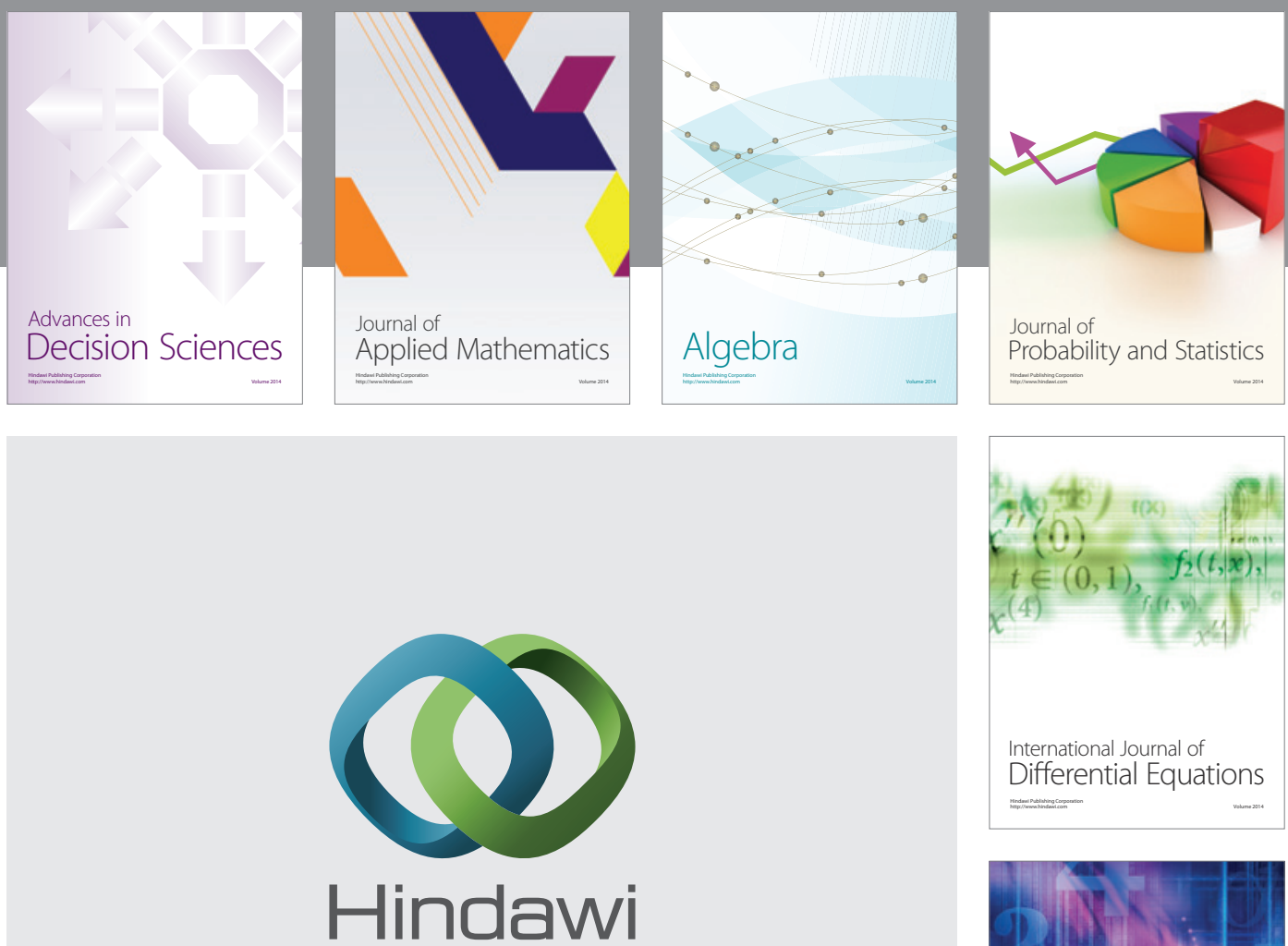

Submit your manuscripts at http://www.hindawi.com
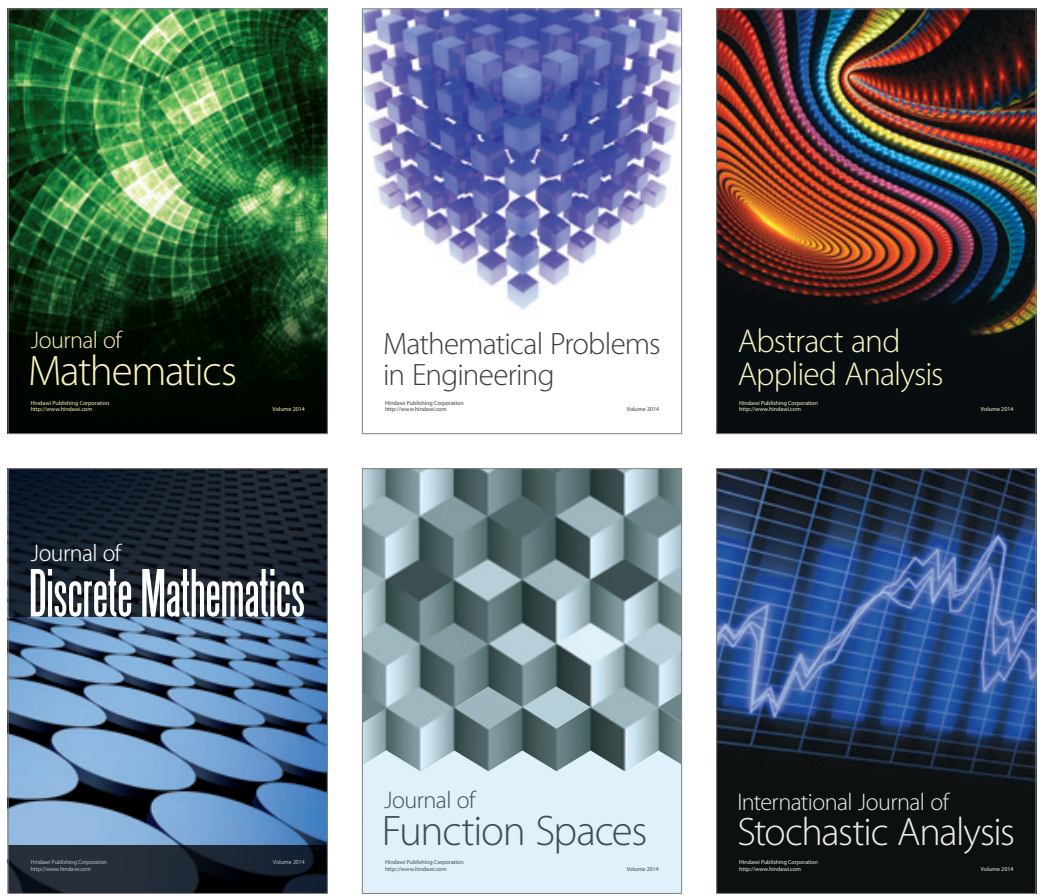

Journal of

Function Spaces

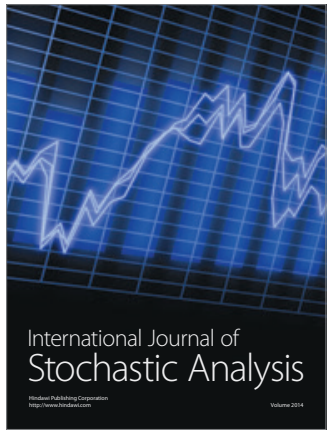

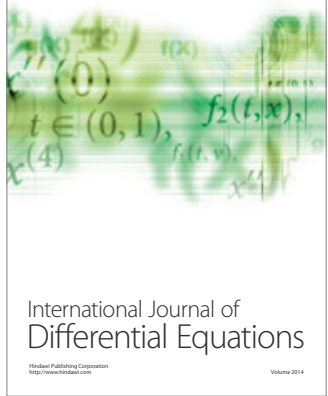
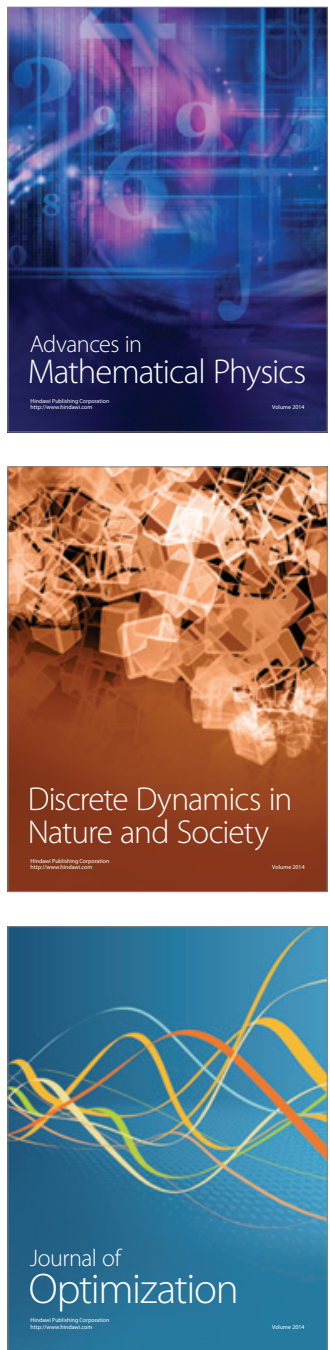